\title{
Editorial: Emerging Technologies With High Impact for Ocean Sciences, Ecosystem Management, and Environmental Conservation
}

\author{
Oscar Pizarro ${ }^{1}$ and Leonard Pace ${ }^{2 *}$ \\ ${ }^{1}$ Australian Centre for Field Robotics, The University of Sydney, Sydney, NSW, Australia, ${ }^{2}$ Schmidt Ocean Institute, Palo Alto, \\ $C A$, United States
}

Keywords: technology, ocean science, ocean observation, ecosystem management, conservation

Editorial on the Research Topic

Emerging Technologies With High Impact for Ocean Sciences, Ecosystem Management, and Environmental Conservation

Earth's oceans are essential for sustaining life as we know it. It's difficult to overstate their value, we rely on our oceans to maintain the planet habitable by regulating its climate and atmospheric composition. We also feed ourselves directly or indirectly through fishing and aquaculture, move vast amounts of energy, raw materials and goods across the globe on ships, enjoy recreation and sports on beaches and on (and under) waves. Our oceans, unfortunately, also continue to act as the final resting place for much of our waste.

While humanity no longer sees them as a boundless resource to use and abuse, our

OPEN ACCESS

Edited and reviewed by: Oscar Schofield,

Rutgers, The State University of New Jersey, United States

${ }^{*}$ Correspondence: Leonard Pace Ipace@schmidtocean.org

Specialty section:

This article was submitted to

Ocean Observation,

a section of the journal Frontiers in Marine Science

Received: 24 February 2021 Accepted: 26 March 2021 Published: 24 May 2021

Citation:

Pizarro O and Pace L (2021) Editorial:

Emerging Technologies With High Impact for Ocean Sciences,

Ecosystem Management, and

Environmental Conservation.

Front. Mar. Sci. 8:671877.

doi: 10.3389/fmars.2021.671877 understanding of the oceans and our ability to manage and conserve marine ecosystems are challenged by their very scale and dynamic nature. The IPCC Special Report on the Ocean and Cryosphere in a Changing Climate highlights increasing observational capacity as a solution for providing the data to improve understanding and modeling of the gaps in knowledge of climate feedbacks in biological systems, and the capacity and limits of biological adaptation for many ecosystems (Bindoff et al., 2019). Many of the observational tools in use today are not reliable for long-term unattended use at sea or cost-efficient enough for scalable deployment. While modern systems capture a wealth of information; i.e., satellites providing constant high resolution coverage at the surface but unable to penetrate depths, the Argo network collecting vast temporal data but providing only point scale data per float, autonomous systems providing high resolution data capture over increasing scales but requiring maintenance for biofouling and system wear, there is ample room for enhancement. Improved scientific understanding and technological innovation offer opportunities to deliver quality marine observations at optimal resolution and coverage, analyze them at scale, and apply the resulting insights to inform timely ecosystem management, conservation, restoration, and marine science.

This Research Topic showcases examples of innovation in scalable, practical, and cost-efficient ocean observation techniques that enable transformative improvement in the understanding of the oceanic processes and marine ecosystems, such as low cost robotic marine survey platforms and workflows, Chérubin et al., intelligent sensing technologies and methodologies, Zhang et al., resource-efficient planning and execution of marine survey and monitoring, Zappa et al., effective observational practices and methodologies that are easy to use and transfer to broad user communities with reduced expertise and training requirements, Williams et al., intelligent and intuitive data analytical tools and services, Schoening, and other related innovations with high impact potential for ocean sciences, ecosystem management, and environmental conservation. 
Together, these advances and insights represent real progress and reasons for optimism in the development of better tools and approaches in support of marine science and conservation. Contributions like the ones highlighted here and ones yet to come increase the odds that we will address some of the many environmental challenges along the way to a sustainable global civilization.

\section{REFERENCES}

Bindoff, N. L., Cheung, W. W. L., Kairo, J. G., Arístegui, J., Guinder, V. A., Hallberg, R., et al. (2019). "Changing ocean, marine ecosystems, and dependent communities," in IPCC Special Report on the Ocean and Cryosphere in a Changing Climate, eds H.-O. Pörtner, D. C. Roberts, V. Masson-Delmotte, P. Zhai, M. Tignor, E. Poloczanska, K. Mintenbeck, A. Alegría, M. Nicolai, A. Okem, J. Petzold, B. Rama, and N. M. Weyer (in press).

\section{AUTHOR CONTRIBUTIONS}

LP and OP contributed to the drafting and completion of the editorial. OP wrote the first draft of the manuscript. LP edited and made additions to sections of the editorial. Both authors contributed to editorial revision, read, and approved the submitted version.

Conflict of Interest: The authors declare that the research was conducted in the absence of any commercial or financial relationships that could be construed as a potential conflict of interest.

Copyright (c) 2021 Pizarro and Pace. This is an open-access article distributed under the terms of the Creative Commons Attribution License (CC BY). The use, distribution or reproduction in other forums is permitted, provided the original author(s) and the copyright owner(s) are credited and that the original publication in this journal is cited, in accordance with accepted academic practice. No use, distribution or reproduction is permitted which does not comply with these terms. 